\section{Commentary: Put your back into it: Erector spinae muscle density and lung transplant survival}

\author{
Caitlin M. Griffin, MD, and \\ Victor H. van Berkel, MD, PhD
}

Current data indicate the median survival of patients after lung transplants to be 6.7 years. ${ }^{1}$ The selection of optimal transplant candidates remains challenging, with many models of patient evaluation currently employed. Indicators of frailty are frequently used to act as prognostic indicators for solid-organ transplant, ${ }^{2,3}$ with increased frailty having been demonstrated to be associated with prolonged ventilation and length of stay post-transplant. ${ }^{4}$ Generalized sarcopenia and muscle density have successfully been used as frailty indicators, with Hsu and colleagues ${ }^{5}$ demonstrating a significant association between psoas muscle sarcopenia and poor outcomes following lung transplantation. While the majority of studies on sarcopenia have focused on the psoas muscles, erector spinae muscle density has been used to evaluate sequelae of patients with chronic obstructive pulmonary disease, again showing strong association with negative outcomes including mortality. ${ }^{6}$

In this issue of the Journal, Oshima and colleagues ${ }^{7}$ propose erector spinae muscle density as a novel prognostic indicator for patient outcomes following lung transplant. In a single-center, retrospective observational study, the investigators evaluated erector spinae muscle density $\left(\mathrm{ESM}_{\mathrm{CT}}\right)$ on pre-lung transplant computed tomography (CT) imaging. Ultimately, 96 patients were included in the study, with

\footnotetext{
From the Department of Cardiovascular and Thoracic Surgery, University of Louisville School of Medicine, Louisville, Ky.

Disclosures: The authors reported no conflicts of interest.

The Journal policy requires editors and reviewers to disclose conflicts of interest and to decline handling or reviewing manuscripts for which they may have a conflict of interest. The editors and reviewers of this article have no conflicts of interest.

Received for publication Aug 2, 2021; revisions received Aug 2, 2021; accepted for publication Aug 3, 2021; available ahead of print Aug 8, 2021.

Address for reprints: Victor H. van Berkel, MD, PhD, Department of Cardiovascular and Thoracic Surgery, University of Louisville School of Medicine, 201 Abraham Flexner Way, Suite 1200, Louisville, KY 40202 (E-mail: victor.vanberkel@ uoflhealth.org).

J Thorac Cardiovasc Surg 2022;164:312-3

$0022-5223 / \$ 36.00$

Copyright (C) 2021 by The American Association for Thoracic Surgery

https://doi.org/10.1016/j.jtcvs.2021.08.001
}

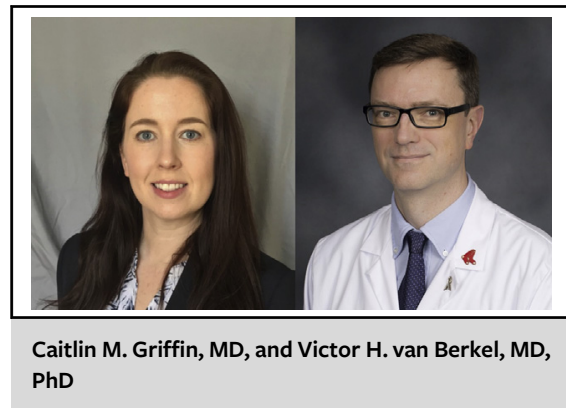

CENTRAL MESSAGE

Erector spinae muscle density may predict lung transplant survival.

approximately one half $(n=49)$ undergoing single-lung transplant. All patients were then allocated to a "low" or "high" ESM $_{\mathrm{CT}}$ density group based on median measured Hounsfield units. These data were then correlated with outcomes including overall survival and complications such as chronic lung allograft dysfunction and infection. Using a stepwise multivariate Cox proportional hazards analysis, the authors found that low $\mathrm{ESM}_{\mathrm{CT}}$ was an independent poor prognostic factor for overall survival as well as chronic lung allograft dysfunction-free survival, despite similar rates of acute rejection and chronic lung allograft dysfunction between the 2 groups. Interestingly, ESM crosssectional area was also measured, but no significant relationship was established between ESM cross-sectional area and survival after lung transplant, suggesting that muscle quality is more important that muscle mass from a survival standpoint.

While this study suggests a novel mechanism for predicting lung transplant outcomes, it is difficult to know how to apply this technique to the larger pretransplant population. For example, the authors divided their population into high and low $\mathrm{ESM}_{\mathrm{CT}}$ groups based on the average $\mathrm{ESM}_{\mathrm{CT}}$ in their patients; it is hard to know the relevance of this division point in patients at other institutions. It would be valuable to know if there is a threshold $\mathrm{ESM}_{\mathrm{CT}}$ below which patients are at increased risk, but that information will only come from careful analysis of a much larger, multiinstitutional dataset. It is also not clear whether low $\mathrm{ESM}_{\mathrm{CT}}$ serves as a marker for frailty - a measure that could be tracked, for example, as a patient undergoes rehabilitation to assess their potential for improvement-or if $\mathrm{ESM}_{\mathrm{CT}}$ represents an intrinsic characteristic of the muscles of the 
patient that is unchangeable. The authors are careful to note that while $\mathrm{ESM}_{\mathrm{CT}}$ correlates with improved post-lung transplant outcomes, the mechanism behind it remains uninvestigated.

Patient outcomes from lung transplant remain difficult to predict with current statistical models, and any patient characteristic that helps better determine organ allocation is valuable to the field. While further studies are needed, this paper suggests that taking a simple measurement, on a study that each pre-lung transplant patient already has, may help determine which patients will have a better outcome.

\section{References}

1. Chambers DC, Cherikh WS, Harhay MO, Hayes D Jr, Hsich E, Khush KK, et al. The International Thoracic Organ Transplant Registry of the International Society for Heart and Lung Transplantation: thirty-sixth adult lung and heart-lung trans- plantation report-2019; focus theme: donor and recipient size match. J Heart Lung Transplant. 2019;38:1042-55.

2. Kaido T, Tamai Y, Hamaguchi Y, Okumura S, Kobayashi A, Shirai H, et al Effects of pretransplant sarcopenia and sequential changes in sarcopenic parameters after living donor liver transplantation. Nutrition. 2017;33: 195-8.

3. Kelm DJ, Bonnes SL, Jensen MD, Eiken PW, Hathcock MA, Kremers WK, et al Pre-transplant wasting (as measured by muscle index) is a novel prognostic indicator in lung transplantation. Clin Transplant. 2016;30:247-55.

4. Pienta MJ, Zhang P, Derstine BA, Enchakalody B, Weir WB, Grenda T, et al. Analytic morphomics predict outcomes after lung transplantation. Ann Thorac Surg. 2018;105:399-405.

5. Hsu J, Krishnan A, Lin CT, Shah PD, Broderick SR, Higgins RSD, et al. Sarcopenia of the psoas muscles is associated with poor outcomes following lung transplantation. Ann Thorac Surg. 2019;107:1082-8.

6. Tanimura K, Sato S, Fuseya Y, Hasegawa K, Uemasu K, Sato A, et al. Quantitative assessment of erector spinae muscles in patients with chronic obstructive pulmonary disease. novel chest computed tomography-derived index for prognosis. Ann Am Thorac Soc. 2016;13:334-41.

7. Oshima Y, Sato S, Chen-Yoshikawa TF, Nakajima D, Nankaku M, Date H, et al. Erector spinae muscle radiographic density is associated with survival after lung transplantation. J Thorac Cardiovasc Surg. 2022;164:300-11.e3.

\section{Commentary: Determining surgical robustness with chest computed tomography}

\author{
Michael A. Smith, MD
}

Perhaps we should be concerned that we rely heavily on radiographic imaging, potentially at the expense of a good history and physical exam, in surgical decision making; however, I read with great interest the article by Oshima and colleagues. ${ }^{1}$ Here they describe a correlation between the density of erector spinae muscles seen on preoperative computed tomography (CT) imaging and outcomes after lung transplantation. Their findings that recipients with lower erector spinae muscle density had less-favorable

From the St Joseph's Hospital and Medical Center, Norton Thoracic Institute, Phoenix, Ariz.

Disclosures: The author reported no conflicts of interest.

The Journal policy requires editors and reviewers to disclose conflicts of interest and to decline handling or reviewing manuscripts for which they may have a conflict of interest. The editors and reviewers of this article have no conflicts of interest.

Received for publication Aug 9, 2021; revisions received Aug 9, 2021; accepted for publication Aug 10, 2021; available ahead of print Aug 14, 2021.

Address for reprints: Michael A. Smith, MD, St Joseph's Hospital and Medical Center, Norton Thoracic Institute, $350 \mathrm{~W}$ Thomas Rd, Ste 500, Phoenix, AZ 85013 (E-mail: michael.smith011@dignityhealth.org).

J Thorac Cardiovasc Surg 2022;164:313-4 $0022-5223 / \$ 36.00$

Copyright (c) 2021 Published by Elsevier Inc. on behalf of The American Association for Thoracic Surgery

https://doi.org/10.1016/j.jtcvs.2021.08.027

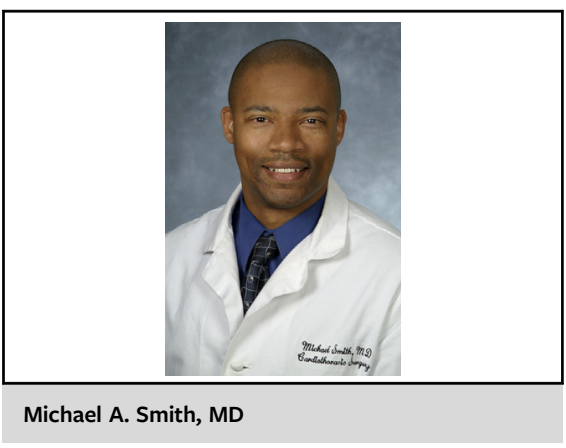

CENTRAL MESSAGE

The authors present an intriguing correlation between erector spinae muscle quality, characterized by radiographic density on CT images, and lung transplantation outcomes.

long-term survival and rates of chronic lung allograft dysfunction are reasonable, plausible, and intriguing.

The erector spinae muscles are important antigravity muscles of the spine. The authors characterize the radiographic density of the erector spinae muscles using Hounsfield units measured on CT imaging to indicate muscle quality or lack of fatty infiltration. This is convenient given 